\title{
Research
}

\section{Predator-Resembling Aversive Conditioning for Managing Habituated Wildlife}

\author{
$\underline{\text { Elsabé Louise Kloppers }}^{1}, \underline{\text { Colleen Cassady St. Clair }}^{1}$, and Thomas Eric Hurd $^{2}$
}

\begin{abstract}
Wildlife habituation near urban centers can disrupt natural ecological processes, destroy habitat, and threaten public safety. Consequently, management of habituated animals is typically invasive and often includes translocation of these animals to remote areas and sometimes even their destruction. Techniques to prevent or reverse habituation and other forms of in situ management are necessary to balance ecological and social requirements, but they have received very little experimental attention to date. This study compared the efficacy of two aversive conditioning treatments that used either humans or dogs to create sequences resembling chases by predators, which, along with a control category, were repeatedly and individually applied to 24 moderately habituated, radio-collared elk in Banff National Park during the winter of 2001-2002. Three response variables were measured before and after treatment. Relative to untreated animals, the distance at which elk fled from approaching humans, i.e., the flight response distance, increased following both human and dog treatments, but there was no difference between the two treatments. The proportion of time spent in vigilance postures decreased for all treatment groups, without differences among groups, suggesting that this behavior responded mainly to seasonal effects. The average distance between elk locations and the town boundary, measured once daily by telemetry, significantly increased for human-conditioned elk. One of the co-variates we measured, wolf activity, exerted counteracting effects on conditioning effects; flight response distances and proximity to the town site were both lower when wolf activity was high. This research demonstrates that it is possible to temporarily modify aspects of the behavior of moderately habituated elk using aversive conditioning, suggests a method for reducing habituation in the first place, and provides a solution for Banff and other jurisdictions to manage hyperabundant and habituated urban wildlife.
\end{abstract}

Key Words: Banff National Park; Canada; Cervus elaphus; behavior; aversive conditioning; dogs; predation; chase sequence; habituation; urban wildlife;

\section{INTRODUCTION}

An emerging problem in many urban areas and parks in North America is the habituation of wildlife to humans and human use areas (Bounds and Shaw 1994, Thompson and Henderson 1998). Habituation is defined in this context as the waning of an animal's innate response to repeated exposure to stimuli that carry no discernable biological consequence (e.g., Whittaker and Knight 1998, Taylor and Knight 2003). Animals that are habituated to humans thus do not avoid contact with humans or areas in which contact with them is likely, unlike the behavior of wilder conspecifics. Habituation of this sort typically produces several ecological and public safety problems. Ecologically, areas with humanhabituated wildlife may exhibit a "refuge effect," in which concentrations of wildlife such as deer (Oidocoileus spp.) or elk (Cervus elaphus) are attracted to artificially fertilized lawns and gardens as food supplements (Lubow et al. 2002, Rubin et al. 2002). In such locations, they also receive artificial refuge from predation (Isbell and Young 1993, Riley et al. 1998) and often cease migratory behavior (Geist 1982). This can lead to breakdowns in natural predator-prey relationships and hyperabundant populations (e.g., Ripple and Beschta 2004), causing declines in the diversity of 
associated wildlife and vegetation species (e.g., Caughley 1981, Warren 1991, Soulé et al. 2003). As public safety problems, habituated animals can be associated with wildlife-vehicle collisions (Etter et al. 2002), the transmission of diseases (Steere 1994), the attraction of dangerous predators to human use areas (McCullough et al. 1997), and, in certain circumstances, aggression or attacks directed at humans (e.g., Herrero 1985, Bounds and Shaw 1994, McNay 2002b).

The prevalence of both types of problems appears to be rising in North America, particularly for elk (Thompson and Henderson 1998), and was conspicuous by the mid 1990s in the town site of Banff in Banff National Park, Canada. Concentrations of habituated elk used the town as a refuge from predation (e.g., McKenzie 2001), ceased to migrate (Woods 2001), and overgrazed the native vegetation (White et al. 1998), with cascading effects on other herbivores such as moose (Hurd 1999) and beaver (Nietvelt 2001). Concerns for public safety were also high because elk injured an average of seven people per year between 1993 and 2001 (G. Peers, unpublished manuscript) and attracted predatory carnivores to the town site (McNay 2002a). Interestingly, similar problems of habituation do not seem to afflict European red deer (also Cervus elaphus), even where average ungulate densities are comparable to that of North America (Staines and Welch 1989). Possible reasons for this include higher human hunting pressure (e.g., Messmer et al. 1997, Morellet and Guibert 1999) and lower predation pressure immediately surrounding human use areas (e.g., Okarma 1995) in European jurisdictions. In combination, these factors may not create the same ungulate-human overlap and habituation within urban areas seen in many parts of North America.

Despite the growing need to prevent ungulate habituation to humans and human use areas in Banff and other parts of North America, relatively little published research has addressed methods by which this can be accomplished (Thompson and Henderson 1998). Reactionary methods typically used to manage "problem wildlife" include translocations (e.g., Baker and Fritsch 1997) or destruction (e.g., Rondeau and Conrad 2003), but these address the consequences, not the causes, of habituation. Moreover, such methods can have negative ecological and social consequences (e.g., Lee and Millar 2003, Rondeau and Conrad 2003) that may be ethically unacceptable to the public
(Guynn and Yarrow 1997, Witmer and Whittaker 2001). Finally, many protected areas in North America must satisfy dual mandates to maintain ecological integrity and visitor enjoyment (e.g., National Park Service 1991, Government of Canada 2000). This balance challenges managers to find alternate methods of redistributing and managing "wild" ungulate populations so that they do not exhibit conflict in human use areas, yet remain accessible to carnivores within the ecosystem and to park visitors seeking to view wildlife. One approach to achieving this balance is to create and maintain higher levels of wariness in urban wildlife without removing them from the system altogether.

Here we describe a research project predicated on the assumption that it is possible to reverse and prevent the habituation process with predatorresembling aversive conditioning. Aversive conditioning is a form of operant conditioning (for background, see Brush 1971, Davey 1981) that can involve either avoidance conditioning or punishment (Domjan 2003). Because elk, like all animals, are adapted to conserve energy, access essential resources, and avoid injury (Geist 1982), we hypothesized that habituated elk that experience negative predator-resembling stimuli such as anxiety, stress, pain, energy loss, and reduced foraging time unpredictably when they are approached by humans or are close to human use areas should learn to avoid these contexts. We believed that such an association would be possible because others have shown that human disturbance can evoke predator-avoidance responses even in the absence of predation events (Frid and Dill 2002, Beale and Monaghan 2004). To capitalize on likely combinations of genetic disposition, learned behavior, and cultural transmission (sensu Whittaker and Knight 1998, Griffin 2004), we selected stimuli known to trigger natural predatoravoidance responses in nonhabituated "wild" ungulates: a fear of humans (Schultz and Bailey 1978, MacArthur et al. 1982, Gander and Ingold 1997) and of human-dog combinations (Martinetto and Cugnasse 2001, Miller et al. 2001). We then drew from principles of stock herding (McConnell and Baylis 1985, Smith 1998) and learning psychology (Domjan 2003) to use these stimuli in a chase sequence that we expected would resemble predatory behavior by humans, human-dog combinations, or wolves (Canis lupus). Our objectives were to (1) test the hypothesis that habituated elk behavior can be reduced with aversive conditioning and (2) compare the efficacy 
of two treatment types: human- and dog-based aversive conditioning. To assess the relative effectiveness of these two techniques, we measured three response variables for the elk: flight response distance from an approaching human (e.g., Altmann 1958), the proportion of time spent in vigilance postures as a measure of predator-wariness (e.g., Frid 1997), and proximity to the town boundary based on daily radio-telemetry locations.

\section{METHODS}

\section{Study area and schedule}

Fieldwork was conducted in the town site and surrounding area of Banff, Alberta $\left(51^{\circ} 15^{\prime} \mathrm{N}, 116^{\circ}\right.$ $30^{\prime}$ W), within Banff National Park, Canada, during the winter of 2001-2002. Banff town site is situated in the Bow Valley within the central Canadian Rockies at an elevation of $1383 \mathrm{~m}$. In the lower Bow Valley bottomlands, modest snowfall combined with occasional warm periods creates important winter habitat for ungulates (Holland and Coen 1983, Holroyd and Van Tighem 1983, Woods 1991). The town of Banff has a permanent human population of 7135, but park visitation approaches $5 \times 10^{6}$ people per year (Banff-Lake Louise Tourism Bureau, personal communication). Our 466.5 ha study area was composed of the urban land-use area of Banff in addition to an adjacent golf course, montane wetlands, forests, and shrublands within 2 $\mathrm{km}$ of the town boundary. The total elk population in the town site area numbered 277 in the spring survey of 2001, showing a continuing decline in response to management actions and increased predation by wolves since a high of 533 elk in 1994 (Banff National Park, unpublished data). During this 2001-2002 field season, up to 18 wolves (Canis lupus) used the area surrounding the Banff town site (Banff National Park, unpublished data).

We collected preconditioning (before) data on three response variables (below) during the months of September and October and postconditioning (after) data between November and March. The winter season was specifically chosen for this conditioning research to coincide with the time that partially migratory elk in Banff are most likely to concentrate in the lower-elevation urban areas (Woods 1991, McKenzie 2001, see also Kilpatrick and Spohr 2000), thus risking habituation to humans and their infrastructure.

\section{Radio-collaring and treatment assignment}

We radio-collared 19 moderately habituated elk between September and December of 2001 using ground-darting immobilization; including five animals that had previously been collared, this provided a total sample size of 24 adult $(>2 \mathrm{yr})$ female elk that were without calves. We defined "moderately" habituated elk as those that had no known histories of year-round town site residency, yet allowed human approach close enough for ground-darting $(<40 \mathrm{~m})$. Although the collaring process itself could be expected to affect elk behavior (e.g., Mech et al. 2002), it was done consistently for elk in all treatment groups including the control, and is thus expected to have the same relative impact on our response variables. It was our subjective impression that the 24 study elk associated in large mixed herds that moved freely throughout the Banff town site and periphery both at the time of collaring and throughout the winter research. Thus, we expected that elk from the different treatment groups were subjected to relatively similar habitat, forage availability, predation pressure, and other environmental factors that could influence our dependent variables. We evaluated this assumption using a home-range overlap analysis to assess the relative similarity of habitat use between elk from the different treatment groups. We divided the 24 study elk into three treatment groups of eight elk each: human, dog, and control. The division was based haphazardly on the locations of three loose groupings of radio-collared elk on the first day of conditioning trials. On that day, these arbitrary groups were all located $<200$ $\mathrm{m}$ from the town boundary and were separated by $<1000 \mathrm{~m}$. Prior and subsequent to our start day, these elk dissolved into one or more large mixed herds, and each elk was treated independently or in groups of a few individuals. We evaluated the independence of the treatment groups with an association analysis to determine how the proportion of time that individual elk spent with elk from their own treatment groups compared with the proportion spent with elk from the other treatment groups.

\section{Aversive conditioning protocols}

We applied 10 15-min aversive conditioning treatments per elk between November 2001 and March 2002 when elk were found within an arbitrary boundary around the town. To create long-lasting 
and robust associations, we attempted to subject the elk to diligent yet unpredictable conditioning events (Brush 1971, Reynolds 1975), and researcher personnel and clothing were alternated between successive trials to help generalize the treatments to other humans (Rybarczyk et al. 2003). The human conditioning treatment was applied by two people chasing the target elk for 15 min while using RG 300 Clip Launcher starter pistols from Margo Supplies, High River, Alberta, Canada, to fire five pyrotechnic screamers and five cracker shells over their heads. We fired the screamer shells first to start the elk running and control their direction of travel, and then used the cracker shells toward the end of the treatment to maintain their sense of fear, anxiety, and confusion. If dense traffic, facilities, or people in close proximity posed a safety hazard during the trial, we moved the elk more slowly to the edge of town before firing any shells. The dog conditioning treatment was applied for $15 \mathrm{~min}$ by one researcher and a professional dog handler with two border collies. The dogs silently herded the elk as directed by the dog handler using voice and whistle commands, using stalking behavior and eye contact to emulate wolf hunting (McConnell and Baylis 1985; see also Mech 1970). The border collies were specifically chosen for this research because preliminary trials indicated that the elk responded to their silent movements with a "flight response," whereas elk responded to a different breed of herding dog (the New Zealand huntaway) that barked continuously by stopping, turning, and confronting the dogs aggressively, indicative of a mobbing or "fight response" (see also Geist 1982). The control group received a "sham" treatment with two researchers standing silently within $50 \mathrm{~m}$ of the elk for the same 15-min period. No other conditioning treatment was applied to the control group, but radio-collaring and response variable measurement were conducted in the same way as for the other treatment groups.

During each conditioning trial using humans or dogs, we moved the animals as far and as quickly as possible during the $15 \mathrm{~min}$, typically at a running pace if it was deemed appropriate for animal, human, and property safety. We considered this "chase sequence" component of the treatment to be particularly important for emulating predation events and maximizing elk energy loss and stress. If elk moved into dense hiding cover and we lost sight of them, we snow-tracked and continued the pursuit and application of noise and visual stimuli, again to better emulate predator hunting and stalking (e.g., Bateson and Bradshaw 1997). A demonstration of our predator-resembling chase sequence can be seen here by clicking on the link titled An Elk of a Problem. All aversive conditioning trials were tracked with a handheld global positioning system (GPS), the Trimble GeoExplorer3 from Trimble in Sunnyvale, California, USA, to accurately measure the distance the elk were displaced. The average frequency of treatment application, i.e., days between treatments, was also recorded for each elk.

A final aspect of the conditioning protocol was the separation of elk into treatable units. Because elk from different treatment groups were often found interspersed with one another, a treatment was applied only if the appropriate treatment animals could be gently split away from the other animals. We split animals by walking slowly toward the elk and pushing them apart using subtle body movements and eye contact, which are standard low-stress stock herding principles (Smith 1998; E. L. Kloppers, C. C. St. Clair, and T. E. Hurd, unpublished manuscript). On some occasions, the whole herd reacted to the splitting, and we abandoned the conditioning trial. When we succeeded in splitting the selected treatment animal (s) from the rest of the herd, they were conditioned in a direction away from the remaining herd and the town site, and toward an area of suitable elk grazing habitat. Although this splitting could be considered another form of conditioning, it was done consistently for all treatment groups including the control, and we expected it to have the same relative impact on elk behavior. In Fig. 1, we provide representative photographs of habituated elk in the Banff townsite and examples of human and dog conditioning.

\section{Response variables}

To assess conditioning-induced changes, we collected data on each elk for three response variables: flight response distance, vigilance, and distance to the town site boundary. We collected these data in two temporal phases: for six weeks prior to the application of the conditioning treatments (before), and again during the latter half of the conditioning period (after). Specific details for each variable are provided below. 
Fig. 1. Habituated elk in Banff National Park (A) prior to aversive conditioning research and during (B) human-based and (C) dog-based conditioning events.

\section{A.}

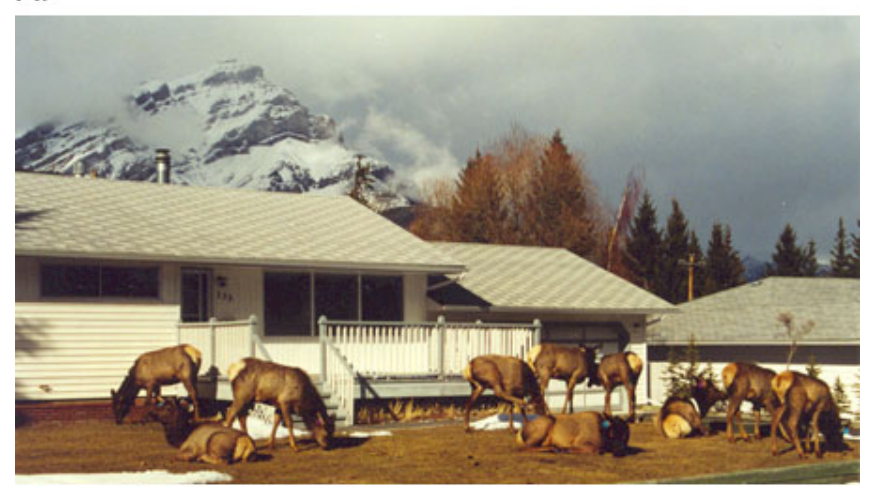

B.

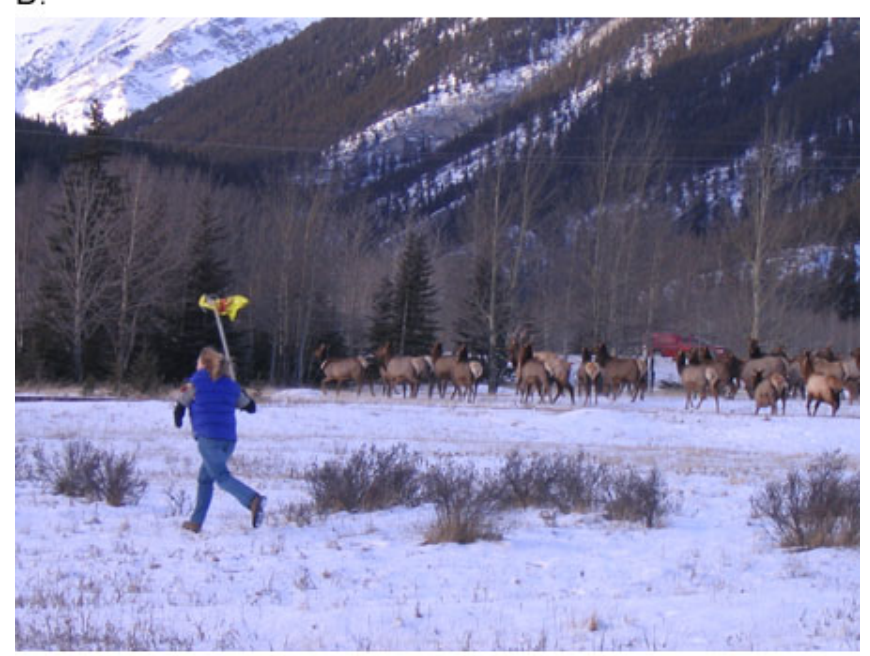

C.

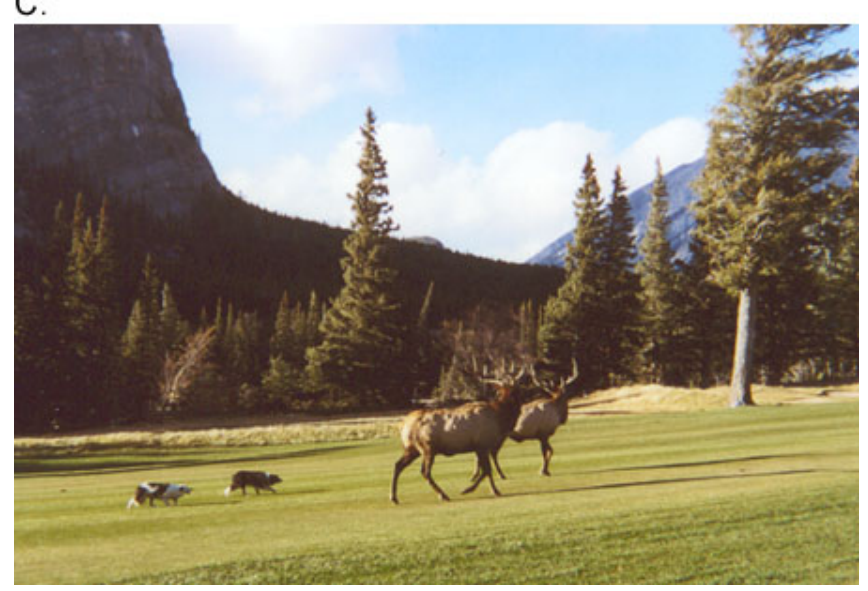

\section{Flight response distance}

Flight response trials were conducted opportunistically throughout the winter, but at a minimum of $24 \mathrm{~h}$ following the application of a conditioning treatment to a given elk. Trials were conducted when the elk was neither bedded down nor traveling, and was $>25 \mathrm{~m}$ away from vegetation cover. When these conditions were met, one person approached the focal elk directly from a minimum distance of $75 \mathrm{~m}$ from the elk. Flight response distance, i.e., the closest distance the elk could be approached before it moved $>5 \mathrm{~m}$ in any direction, was measured with a digital range finder, the Bushnell Yardage Pro 500 from Bushnell Corp., Overland Park, Kansas, USA, which is accurate to within $0.5 \mathrm{~m}$. For analytical purposes, the preconditioning flight response data for each elk were averaged into a "before" value. To assess conditioning-induced change, we attempted to measure the flight response of all elk following their tenth aversive conditioning treatment. However, by that time, many elk had high levels of wariness and concealment in forest cover that precluded the measurement of flight response, particularly for the human- and dog-conditioned elk. Thus, we derived our "after" value from an average of whatever flight response data were available between the fifth and tenth conditioning treatments for each elk. We acknowledge that this metric undoubtedly provides a more conservative measure of treatment effects than might have actually existed after all 10 treatments.

We anticipated that several uncontrolled variables might also influence flight responses (LaGory 1987). Thus, for each trial we recorded herd size, nearest neighbor distance, distance to cover, and relative location within the herd, e.g., periphery, edge, center. Snow depth at the time of each flight response trial was calculated post hoc from an average of snow transect measurements around the town site $(\mathrm{H}$. Breniser, unpublished data). Because the proximity of wolves was likely to influence the behavior of elk (e.g., Lima and Dill 1990), a relative index of wolf presence was also calculated post hoc using trackpad data from wildlife underpasses in the vicinity of the town site (A. Clevenger, unpublished data). Wolves and other animals concentrate their movements toward the town in these underpasses because a $2.4 \mathrm{~m}$ wildlife exclusion fence borders the highway that parallels the Bow Valley through Banff National Park (McGuire and Morrall 2000, Clevenger et al. 2001). To estimate wolf activity using this information, we averaged the number of 
wolf southbound passages, i.e., toward the town site, for the week preceding each flight response trial.

\section{Vigilance}

Vigilance trials were conducted opportunistically throughout the winter, but always more than $24 \mathrm{~h}$ after a conditioning treatment was applied to the target elk. Trials were conducted when the elk was $>25 \mathrm{~m}$ away from vegetation cover and was not bedded down or traveling. The elk was observed from a vehicle or at long range with binoculars or a spotting scope to avoid detection and mitigate the influence of the observer. Each trial was 5 min in length, and was abandoned if the elk bedded down, became aware of the observer's presence, or was disturbed by other human or wildlife activity in the area. The amount of time was recorded for each predominant activity, e.g., feeding, scanning, grooming, defecating, moving, social interaction, and the proportion of time spent scanning or vigilant was calculated. As for flight response, the preconditioning vigilance data for each elk were averaged into a "before" value, and the vigilance data between each elk's fifth and tenth conditioning treatments were averaged into an "after" value. The exact duration of time between average before and after values differs among individual, and we refer to this binary factor as simply the "time period." Again, we anticipated that other variables might influence vigilance behavior, so we recorded herd size, nearest neighbor distance, distance to cover, and relative location within the herd, i.e., periphery, edge, center. Average snow depth and wolf presence values for the time of each trial were calculated as per flight response above.

\section{Proximity to town site}

To assess displacement from the urban area following conditioning, we recorded one morning visual sighting or radio-telemetry location per elk daily between September 2001 and March 2002. These locations were recorded prior to daily measurements of flight response or vigilance behavior or the application of conditioning treatments. From those locations, elk distance to the closest point on the town site boundary was calculated using an ArcGIS Spatial Analyst (Environmental Systems Research Institute, Redlands, California, USA; McCoy and Johnston 2000). Average snow depth and wolf presence values for the time of each location were calculated as per flight response above. Again, the preconditioning distances for each elk were averaged into a "before" value, and the distances after each elk had received 10 conditioning treatments were averaged into an "after" value per elk.

\section{Statistical analyses}

All analyses were conducted using SPSS 11.5 (Norusis 2002). Because of the relatively small sample size of eight animals per group used by this study, we set $\alpha=0.10$ to balance Type I and Type II errors. One-way ANOVA was used in preliminary analyses to compare the average distance moved in each trial among treatments; the proportion of time each elk associated with elk of the same and other treatment groups, i.e., an association analysis; and the proportions of Minimum Convex Polygon home-range overlap within and among the different treatment groups, i.e., home-range overlap analysis. Analyses of all three response variables were conducted using repeated-measures linear mixed models (Norusis 2002). In the flight response and vigilance models, the variables group size, nearest neighbor, distance to cover, location in the group, snow depth, and wolf presence were tested for significant univariate correlations and inclusion as possible co-variates. The variables snow depth and wolf presence were tested for use in the model describing proximity to town site. All biologically plausible two-way interactions were also tested by adding them, one at a time, to the final main effects models and assessing their significance. Flight response data were log-transformed, and vigilance data were square-root-transformed to achieve normality.

\section{RESULTS}

Elk received an average of 8.0 aversive conditioning trials $( \pm 1.2$ trials $S E)$ at the time of postconditioning response variable measurement, with no significant difference between treatment groups $(t=-1.27, P=$ $0.22, n=16)$. During the 15 -min conditioning trials, the dog and human treatments moved the elk average distances of $1219 \mathrm{~m}( \pm 80.3 \mathrm{~m} \mathrm{SE})$ and 1148 $\mathrm{m}( \pm 50.8 \mathrm{~m} \mathrm{SE})$ respectively, whereas the control group elk drifted an average of $49 \mathrm{~m}( \pm 13.7 \mathrm{~m} \mathrm{SE})$ during the sham treatment. We found no significant difference in trial distance between the human- and dog-conditioned groups $\left(F_{1,88}=0.62, P=0.43\right)$, but both the human and dog treatments moved elk 
Fig. 2. Elk flight response distance ( $m \pm S E$ ) before (white column) and after (black column) aversive conditioning treatments were applied to the three treatment groups in Banff National Park.

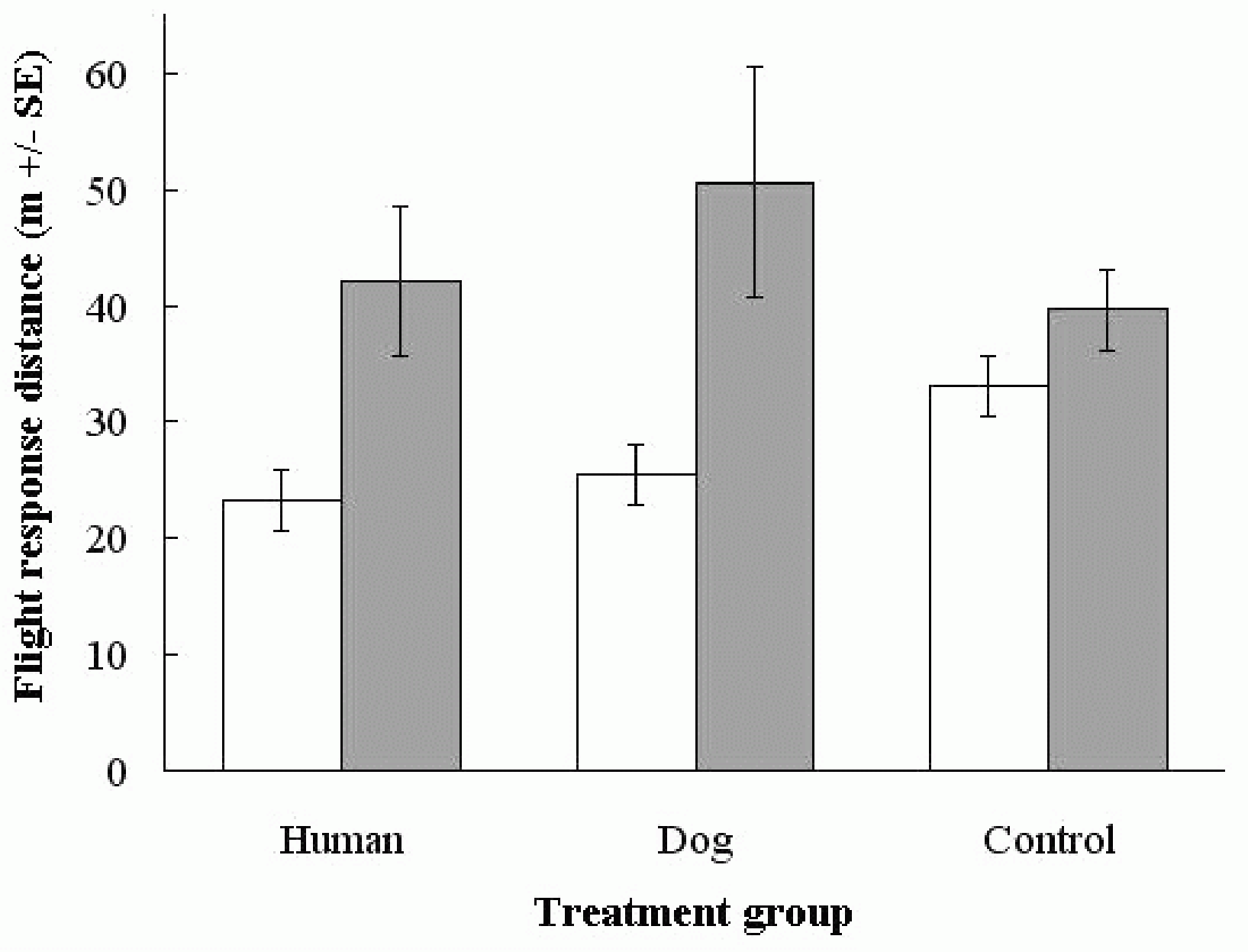

significantly farther than the control group $\left(F_{1,80} \geq\right.$ 229.4, $P \leq 0.001)$. The association analysis examined the proportion of time that elk spent with elk of their own treatment group $(40.2 \%$ average, $\pm 2.1 \% \mathrm{SE}$ ) in comparison with the time spent with elk of the other treatment groups $(35.5 \%$ average, $\pm 1.7 \% \mathrm{SE})$. Five of the six two-way comparisons did not significantly differ $(P \geq 0.367)$, although the human-conditioned treatment group spent a lower proportion of time with elk of the control group than with each other $(P=0.001)$. Average elk Minimum Convex Polygon (MCP) home-range size was 2857.5 ha, and there was no significant difference in home range size among treatment groups $\left(F_{2,23}=\right.$ $0.042, P=0.96)$. The MCP home ranges of the 24 individual research elk overlapped an average of $81.3 \%( \pm 2.9 \% \mathrm{SE})$, and there was no significant difference between the proportions of home range overlap within and among treatment groups $\left(F_{5,551}=\right.$ $0.38, P=0.86)$. Elk were conditioned at an average frequency of one treatment every 9.8 days $( \pm 1.2$ days SE) over the winter field season.

Overall, elk flight response distance increased significantly following treatment application $(F$ 
Fig. 3. Relationship between flight response distance and nearby wolf activity for elk before (circle) and after (square) aversive conditioning in Banff National Park.

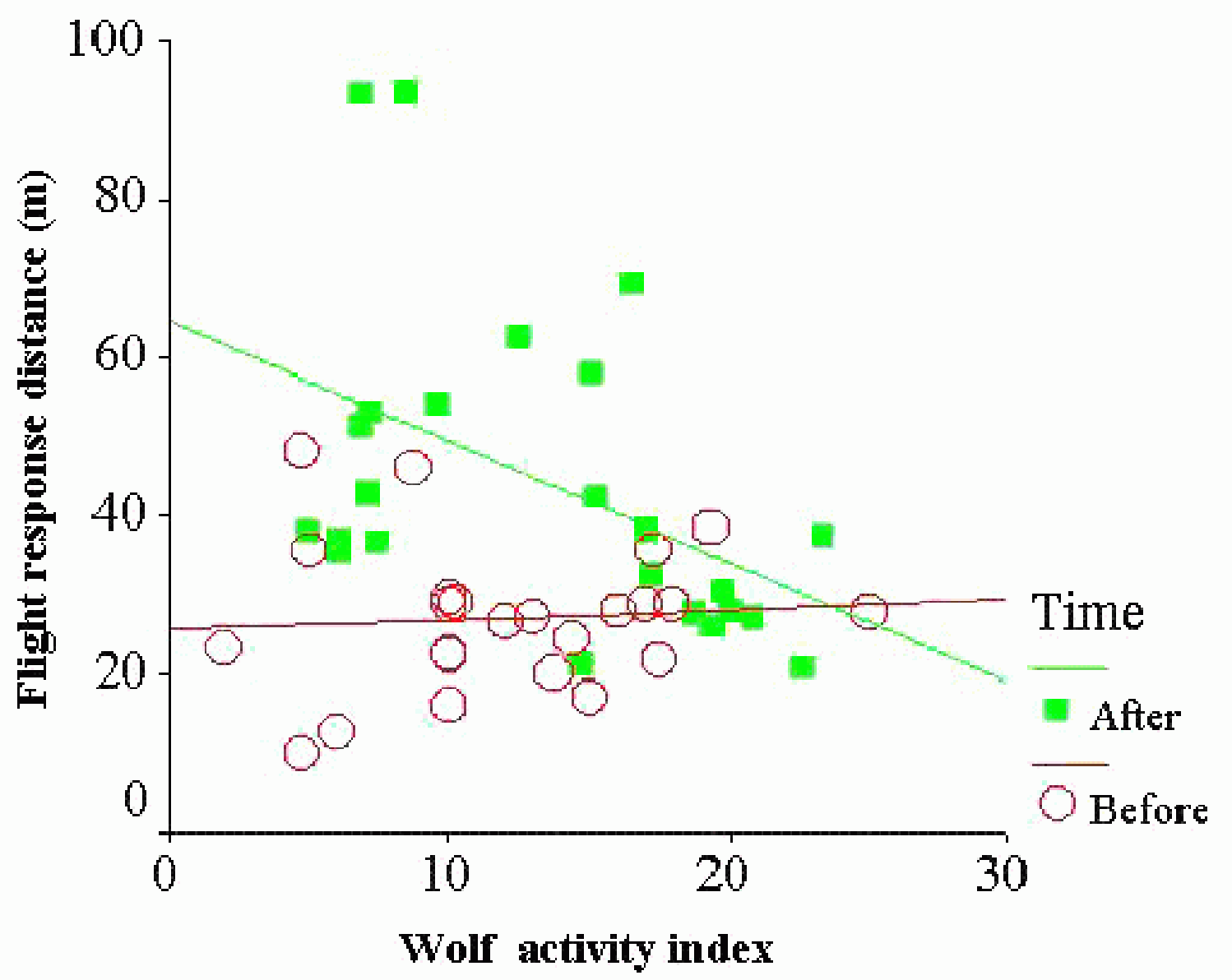

$1.28=23.120, P<0.0001)$, and there was a significant difference in that increase among the treatments, as shown by the significant interaction between treatment and time period (Fig. $2 ; F_{2,22}=10.86, P$ $=0.001)$. As we had predicted, the human- and dogconditioned groups both differed significantly from the control group after conditioning $\left(F_{1,14} \geq 5.63\right.$, $P \leq 0.037)$. However, there was no significant difference between the human- and dogconditioned groups $\left(F_{1,14}=1.10, P=0.31\right)$. On average, the elk in the human- and dog-conditioned groups increased their flight response distance from an approaching human by $22.1 \mathrm{~m}( \pm 5.5 \mathrm{~m} \mathrm{SE})$, an increase of $47.4 \%$. The flight response of elk in the control group negligibly increased by $6.4 \mathrm{~m}( \pm 5.5$ $\mathrm{m} \mathrm{SE})$. The variables group size, distance to cover, nearest neighbor, location in the group, snow depth, and wolf presence were tested for significant univariate correlations. Snow depth was correlated with time (Pearson's $r=0.60$ ) and excluded from the model. To test for possible inclusion as covariates in the model, each remaining variable was entered as a fixed-effect co-variate, singly and in combination with other co-variates, but only wolf 
Fig. 4. Proportion of time elk spent vigilant $(\% \pm S E)$, before (white column) and after (gray column) aversive conditioning treatments were applied to the three treatment groups in Banff National Park.

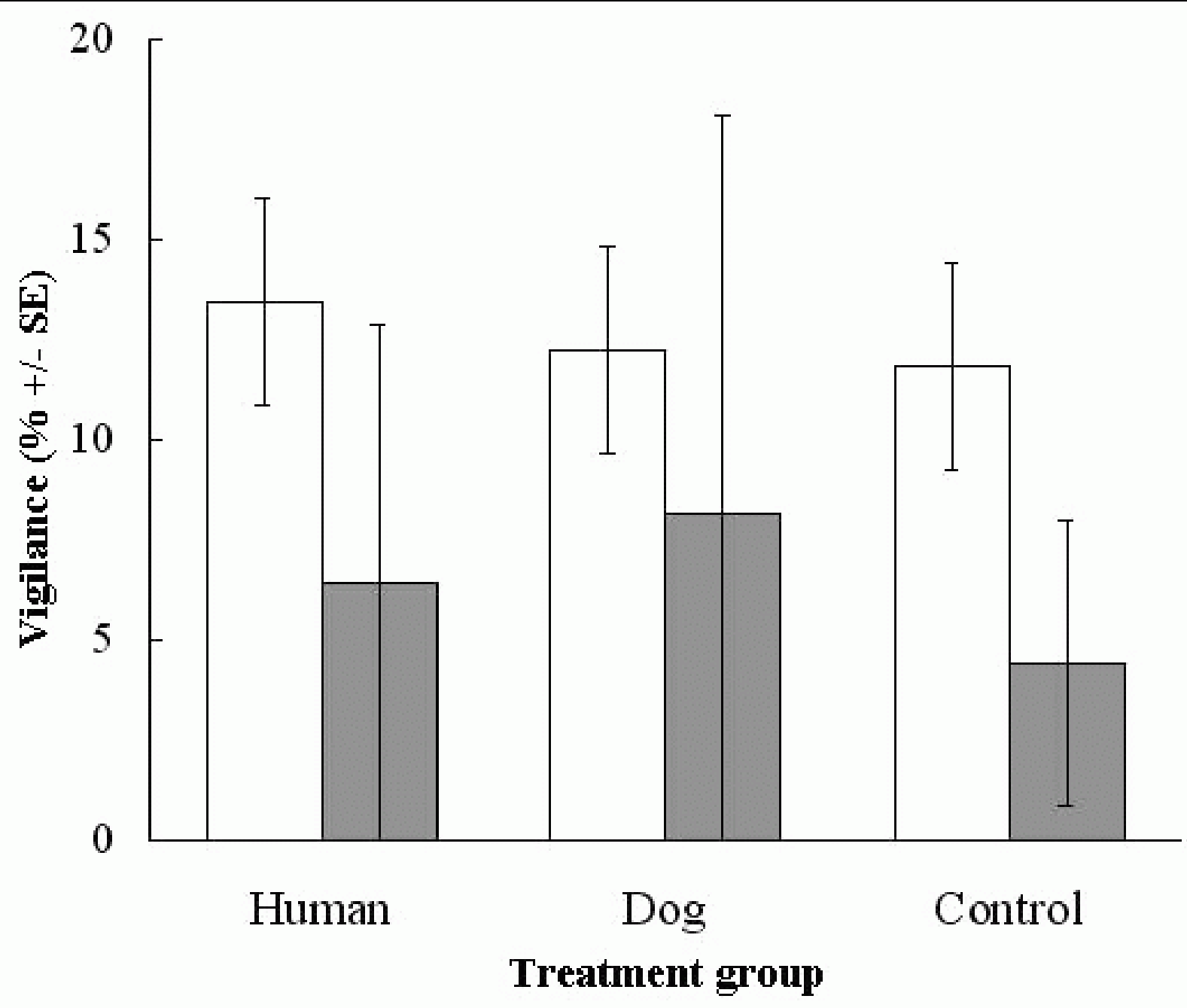

activity significantly and negatively affected flight response distance $\left(F_{1,17}=4.87, P=0.041\right)$. This meant that elk exhibited shorter flight response distances when recent wolf activity was high. There was also a significant interaction between wolf activity and time period (Fig $3 ; F_{1,22}=5.79, P=$ $0.025)$, showing that flight responses declined with increasing wolf activity more strongly after conditioning.

Contrary to our expectation, vigilance declined for all treatment groups after conditioning (Fig. 4; $\left.F_{1,21}=10.11, P=0.005\right)$, and there was no significant difference in the relative decline among treatments (time period by treatment interaction; $\left.F_{2,21}=0.18, P=0.83\right)$. There was, however, a trend indicating that the vigilance of the conditioned animals declined less $(42 \%)$ than that of the control animals $(62 \%)$. The same variables were tested for correlations and inclusion as in the flight response model. Although snow depth was a significant covariate, we excluded it from the model because of a strong correlation with time (Pearson's $r=0.77$ ). 
Fig. 5. Average elk daily distance $(\mathrm{m} \pm \mathrm{SE})$ to the closest point on the town boundary, before (white column) and after (black column) aversive conditioning treatments were applied to the three treatment groups in Banff National Park.

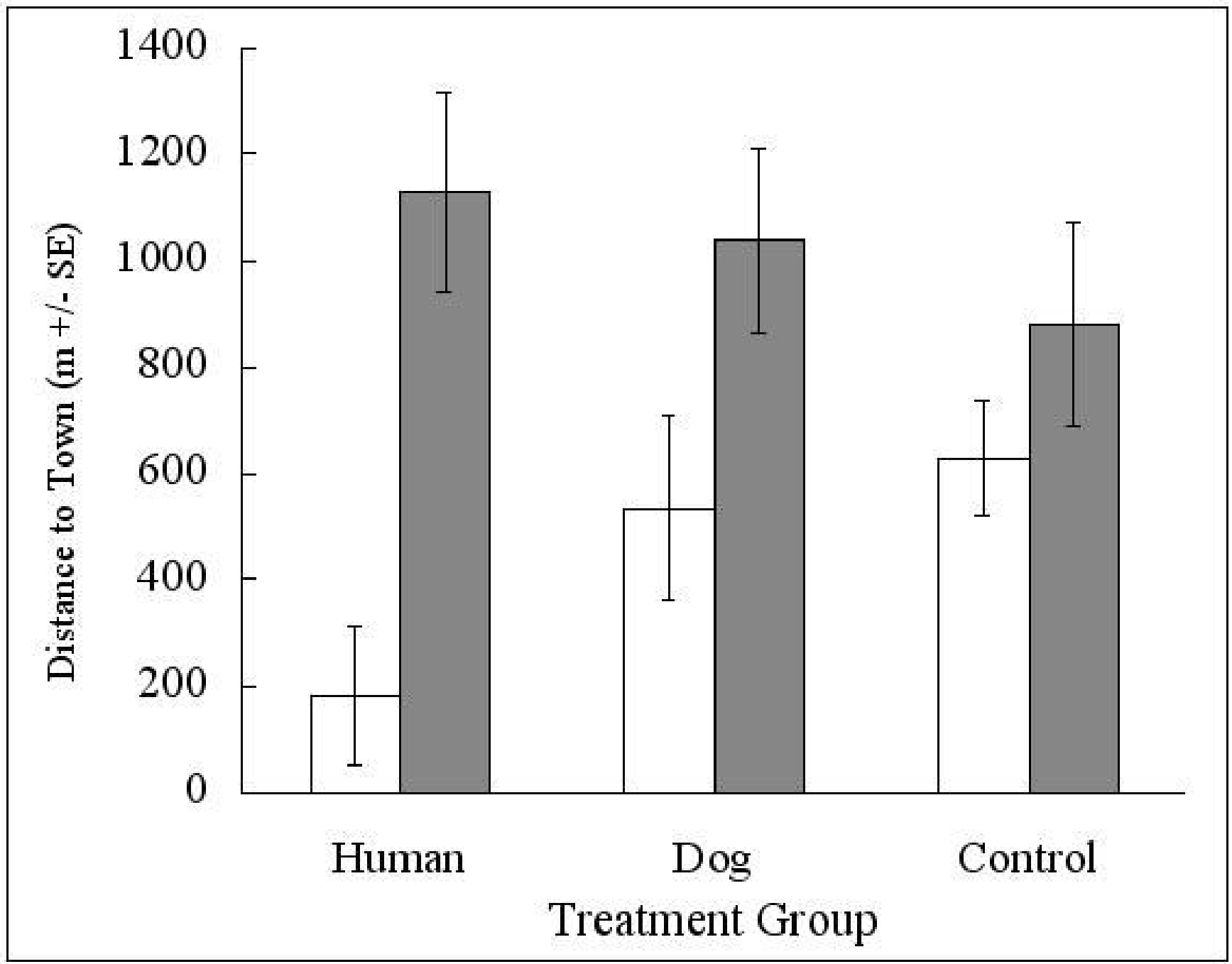

The distance from the daily position of each elk to the town boundary increased significantly after conditioning for all treatment groups (Fig. $5 ; F_{1,31}=$ $11.51, P=0.002)$. As for flight response, there was a significant time period by treatment interaction that revealed a much greater increase for the humanconditioned group $\left(F_{4,27}=2.97, P=0.037\right)$. This group differed significantly from both the dog and control treatments $\left(F_{2,19}>4.12, P<0.034\right)$, with no significant difference between the dog and control treatments $\left(F_{2,18}=0.402, P=0.675\right)$. Snow depth and wolf activity were tested for univariate correlations and possible inclusion in the model, but snow depth was highly correlated with time (Pearson's $r=0.934$ ) and thus excluded. Wolf activity was not significant once entered with the other variables and so was excluded from the final model. However, there was a significant interaction between wolf activity and treatment (Fig. 6; $F_{3,37}=$ $3.35, P=0.029)$, showing that elk occurred at greater distances from town in the human treatment when wolf activity was low. 
Fig. 6. Relationship between the proximity of elk to the town boundary and nearby wolf activity for elk that were subjected to human (red-rimmed circle), dog (green square), and control (blue circle) aversive conditioning treatments in Banff National Park.

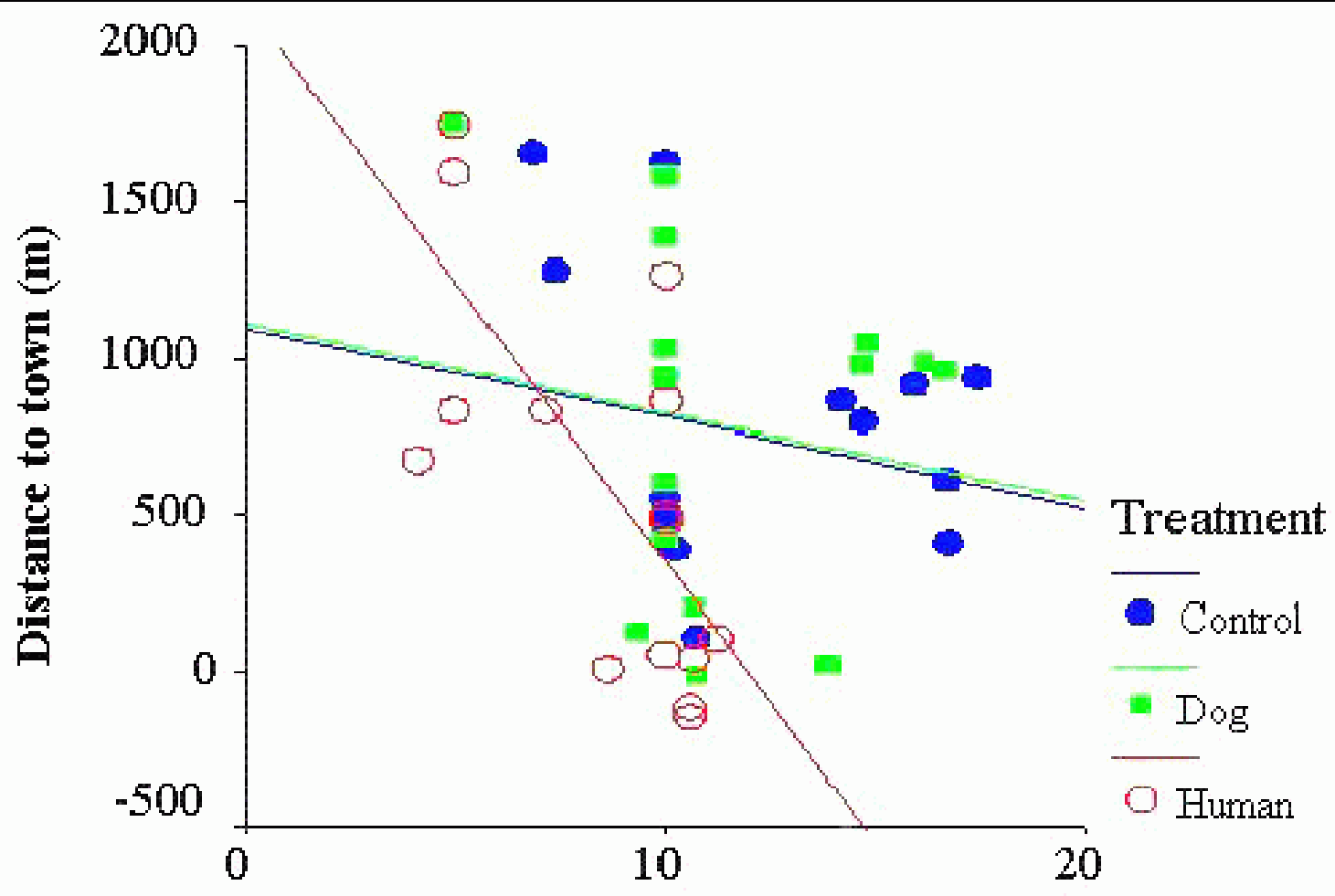

Wolf activity index

\section{DISCUSSION}

Our results suggest that aversive conditioning is capable of modifying some aspects of elk behavior toward humans and human use areas. They also suggest that dog and human conditioning treatments can achieve similar levels of success for our primary measure of habituation, flight response distance. This variable, which showed a significant increase after both conditioning treatments, upheld our predictions that elk would be more wary of humans following aversive conditioning. The similarity in response to both treatments for this variable may stem from the magnitude and consistency of the conditioning effort. In particular, both treatments involved chases with sufficient distance $(1215 \mathrm{~m})$, frequency $(1 / 9.8 \mathrm{~d})$, and duration $(15 \mathrm{~min})$ to emulate or exceed natural predation events by wolves. Prior research in Riding Mountain National Park (Carbyn 1983) showed that the length of lethal wolf chase sequences ranged from 20 to $260 \mathrm{~m}$ in distance. In Banff, the length of these sequences averaged $180 \mathrm{~m}$, with a range of 10 to $1700 \mathrm{~m}$ (M. Hebblewhite, unpublished data; Parks Canada, unpublished data), although both studies acknowledged a potential sample bias toward shorter sequences. Neither of those studies included nonlethal, i.e., unsuccessful, chase sequences, 
which would presumably be much longer (M. Hebblewhite, personal communication). Our average chase sequence length of $1215 \mathrm{~m}$ therefore exceeded that of recorded natural predation events, but was perhaps comparable in length to nonlethal wolf chase sequences.

The average frequency of our conditioning treatments, which occurred once every $9.8 \mathrm{~d}$, may have been similarly important to their efficacy because it also exceeded the average frequency of visitation by wolves to an elk herd (1/13.4 d; Weaver 1994). Although our conditioning treatments did not emulate all aspects of hunting by wolves, the energy loss and stress from our longer and more frequent conditioning events appeared to be severe enough to trigger elk escape and avoidance responses. Longer hunting sequences by humans have generated extraordinarily large volumes of the stress hormone cortisol in red deer (Cervus elaphus), particularly when the animals dashed away only to be repeatedly found and chased again by hunters (Bateson and Bradshaw 1997). Therefore, although our aversive conditioning chase sequences using humans and dogs did not present any direct mortality risk for elk, the procedure may have emulated enough aspects of wolf or human hunting for elk to perceive us as potential predators and display typical antipredator responses (e.g., Beale and Monaghan 2004).

Our interpretation that our chase sequences emulated predation events is consistent with the theory that human-caused disturbance stimuli can be considered a form of predation risk (Frid and Dill 2002, Beale and Monaghan 2004), causing animals to modify their behavior to maximize their security, decrease stress, and maintain their reproductive fitness (Geist 1982, Lima and Dill 1990, Frid and Dill 2002). The predator-resembling nature of the chase sequence in our human and dog conditioning treatments may also explain why the elk in our experiment showed no signs of habituating to the conditioning stimuli, whereas, in other studies, wildlife quickly habituated to the use of auditory (Bomford and O'Brien 1990, Belant et al. 1996, Bender 2003) or visual stimuli (Espmark and Langvatn 1985, Beringer et al. 2003, VerCauteren et al. 2003). A lack of perceived predation risk in those contexts offers a potential explanation for the minimal increase in flight response for the control elk in our study. This missing stimulus may also explain increased signs of habituation and even aggression by some control group elk to researchers during the four-month treatment period. The rapidity of the changes in the treated elk and the apparent change in the other direction by some control elk suggests that elk can habituate to human presence in a nonthreatening environment quickly, which has management implications for Banff and other areas in which large numbers of tourists, golfers, and residents have benign encounters with elk almost daily (see also Geist 1982).

The decrease in the vigilance behavior of all the elk during our treatment period is inconsistent with our predictions, but perhaps consistent with predictable seasonal changes in elk energy budgets related to snow depth (e.g., Goodson et al. 1991). Our baseline data were collected in the fall, when elk have higher energy reserves that may support greater vigilance investments and flight response distances (Parker et al. 1984). In contrast, our conditioning period and related data collection partially coincided with the late winter period, when elk typically begin catabolism of body reserves (DelGiudice et. al 1991, DelGiudice et al. 2000). At that time, they may sacrifice their security, particularly with decreased vigilance, to increase feeding time (e.g., Moen 1976, Gates and Hudson 1979, Lima and Dill 1990, Parker et al. 1996). The strength of these seasonal effects on vigilance relative to treatment effects could conceivably have diminished our ability to detect real differences among the treatment groups (Type II error). To avoid these sources of potential error for this type of research in the future, one would ideally collect all vigilance data within the same season. Although we could not detect a significant difference among treatments, control animals exhibited a $20 \%$ greater decline in vigilance after conditioning than did treated animals (Fig. 3). This implies that elk maintained higher vigilance levels under human and dog conditioning than they did without it, offering qualified support for the utility of aversive conditioning for modifying habituated elk behavior. Unfortunately, the logistical necessity of using vigilance data between the fifth and tenth conditioning treatment of each elk, rather than data following the tenth treatment, may have contributed to the nonsignificant difference among treatment groups.

Our final result, that the human-conditioned elk exhibited significantly greater increases in the distance between their daily positions and the Banff town-site boundary, further supports our initial prediction that aversive conditioning can modify elk behavior by teaching avoidance of human use areas, 
corroborating the results of Nolte et al. (2003). Our result recommends human over dog conditioning and corroborates Frid and Dill's (2002) hypothesis that human disturbance is a form of predation risk. Our human-conditioned elk subsequently avoided those areas in which conditioning had occurred, suggesting some memory of those aversive stimuli and the behavior that successfully avoided them. An alternative, but not mutually exclusive, explanation for the subsequent avoidance of the town by the conditioned elk might reflect the energetic cost of conditioning to the animal, particularly when applied in winter. During the late winter period with lower temperatures and deeper snow, elk could normally be expected to conserve energy by reducing their movement and staying in the areas with the highest relative nutritional quality (Gates and Hudson 1979, Parker et al. 1984, Sweeney and Sweeney 1984, McCorquodale 1993), such as those offered in the town site (McKenzie 2001). When we persistently conditioned the elk more than a kilometer away during that critical period, the energetic cost of repeatedly moving to and from the town site may have outweighed the benefits of returning to it (see also Bunnell and Gillingham 1985, Bradshaw et al. 1998). These results suggest that aversive conditioning can potentially reduce the urban "refuge effect" by both increasing the perceived predation risk and reducing the energetic benefit.

Despite the significant treatment effect we detected for proximity to the town boundary, our association analysis showed some evidence that all treatment groups responded to our conditioning, indicating some herd-level influences (see also Galef 1995, Ralphs and Provenza 1999). Because elk receive both energetic and security benefits from herding into larger groups, particularly in late winter (Moen 1976, Geist 1982, Hebblewhite and Pletscher 2002), it is likely that this phenomenon reduced some of the variation we might otherwise have detected among treatments. An additional explanation for herd-level effects could relate to emphatic learning (e.g., Klopfer 1957) or social facilitation (e.g., Harlow 1932), whereby individuals not exposed to the conditioning treatment learn from the antipredatory behavior of other conditioned herd members (see Muller-Schwarze 1991, Griffin 2004). Nevertheless, regardless of the potential for herd-level effects to influence this research, the high variation we documented among individuals encourages further individual-based research, and strengthens the apparent success of our human- based aversive conditioning protocols for managing hyperabundant wildlife in areas with high human use.

An important co-variate that was apparent in our analyses of both flight response distance and proximity to town was the activity of wolves. In both cases, wolf activity appeared to reduce the efficacy of our conditioning treatments, as might be expected when elk had the option of challenging us vs. real predators. Flight responses decreased when wolf activity was high, suggesting that elk were reluctant to flee from us in the vicinity of predators. This effect was much stronger after conditioning, effectively acting in opposition to our treatment effects. Proximity to town also responded to wolf activity, this time exhibited as an interaction with treatment. This meant that the strong effect of human conditioning was sharply reduced by high wolf activity. Dog and control treatments, which did not show significant postconditioning effects on proximity, were not similarly affected by wolf activity. Again, this result indicates that our effective (human) conditioning would have been even more effective were it not for the counteracting effects of wolves. Banff and other jurisdictions may thus bear in mind that more conditioning effort will likely be needed when it pushes animals in the direction of predators relative to comparable situations without predators.

\section{CONCLUSION}

These results have two main implications for managers. First, because the dog and human aversive conditioning treatments achieved relatively similar levels of success in modifying elk flight responses, the choice of which treatment to apply might be based on economic efficiency and local logistics for jurisdictions contending only with the behavior, and not the location, of urban wildlife. Presumably, professional dog handlers who are willing to use their highly trained border collies for wild elk management are both scarce and expensive. In our system, we calculated the monthly cost of conditioning with dogs to be $\$ 4300.00$ CAD, $15 \%$ higher than the cost of conditioning with humans. Human conditioning in many jurisdictions could also be done without hiring additional staff, which would further lower the associated costs. For these reasons, we chose to use humans for a second season in which we sought to identify the optimal frequency of conditioning for elk with differing levels of initial 
habituation and assessed the extinction of conditioned responses (Kloppers et al., unpublished manuscript).

A second aspect of the choice of conditioning medium for managers of national parks and urban areas is the nature of public perception. For us, the public response to the quiet, friendly appearance of the dog treatment was generally positive, but we received some noise complaints about the cracker and screamer shells associated with the human treatment. Because the predator-resembling chase sequence appears to be the critical component of conditioning and the method used, i.e., cracker shells or dogs, is secondary, managers could also choose a variety of other methods to complement the chase sequence and suit their situation. For example, wardens in Banff National Park typically use raised hockey sticks with bags tied to one end to condition elk by emulating the antler displays common among sparring elk (Geist 1982, Jennings et al. 2002), and Canadians who observe this are generally quite accepting of this form of threat display. Ultimately, budgets, the local situation, and associated management priorities will dictate whether the human or dog aversive conditioning treatment is the most appropriate choice for a given jurisdiction.

Our research suggests that predator-resembling aversive conditioning can provide both an effective and socially appealing alternative to traditionally invasive management techniques for habituated wildlife. By proactively addressing the causal factors rather than just treating the symptoms, aversive conditioning can prevent habituation from occurring, thereby achieving ecological and public safety objectives while maintaining wildlife viewing opportunities and public support. Predatorresembling aversive conditioning ultimately offers managers of urban and protected areas a solution that balances ecological and human dimensions in wildlife management.

Responses to this article can be read online at:

http://www.ecologyandsociety.org/vollo/iss 1/art31/responses/

\section{Acknowledgments:}

We acknowledge the generous financial and logistical support of Banff National Park and the
University of Alberta; the capable and enthusiastic field assistance of J. Mills, P. Ashby, R. Gareau, C. Aikens, and J. Zehnder with herding dogs Blue and Duke; the insightful advice of E. Merrill, S. Bayley, $C$. White, R. Hudson, and four anonymous reviewers; and the operational support of G. Peers, $R$. LeBlanc, I. Syme, D. Herman, D. Eastcott, T. Shury, T. Davidson, T. Gui, and J. Truscott. Some essential equipment was provided by the Canada Foundation for Innovation via a New Opportunities Grant to C. C. St. Clair. This research was funded through Parks Canada MOA \#01-0068, in accordance with the University of Alberta Animal Care Committee Permit \#354111.

\section{LITERATURE CITED}

Altmann, M. 1958. The flight distance in freeranging big game. Journal of Wildlife Management 22(2):207-209.

Baker, S. V., and F. Fritsch. 1997. New territory for deer management: human conflicts on the suburban frontier. Wildlife Society Bulletin $\mathbf{2 5}$ (2):404-407.

Bateson, P., and E. L. Bradshaw. 1997. Physiological effects of hunting red deer (Cervus elaphus). Proceedings of the Royal Society of London Series B-Biological Sciences 264 (1389):1707-1714.

Beale, C. M., and P. Monaghan. 2004. Human disturbance: people as predation-free predators. Journal of Applied Ecology 41:335-343.

Belant, J. L., T. W. Seamans, and C. P. Dwyer. 1996. Evaluation of propane exploders as whitetailed deer deterrents. Crop Protection $\mathbf{1 5}$ (6):575-578.

Bender, H. 2003. Deterrence of kangaroos from agricultural areas using ultrasonic frequencies: efficacy of a commercial device. Wildlife Society Bulletin 31(4):1037-1046.

Beringer, J., K. C. VerCauteren, and J. J. Millspaugh. 2003. Evaluation of an animal- 
activated scarecrow and a monofilament fence for reducing deer use of soybean fields. Wildlife Society Bulletin 31(2):492-498.

Bomford, M., and P. H. O'Brien. 1990. Sonic deterrents in animal damage control: a review of device tests and effectiveness. Wildlife Society Bulletin 18:411-422.

Bounds, D. L., and W. W. Shaw. 1994. Managing coyotes in U.S. National Parks: human-coyote interactions. Natural Areas Journal 14(4):280-284.

Bradshaw, C. J. A., S. Boutin, and D. M. Hebert. 1998. Energetic implications of disturbance caused by petroleum exploration to woodland caribou. Canadian Journal of Zoology 76:1319-1324.

Brush, R. 1971. Aversive conditioning and learning. Academic Press, New York, New York, USA.

Bunnell, F. L., and M. P. Gillingham. 1985. Foraging behavior: dynamics of dining out. Pages 53-79 in R. J. Hudson and R. G. White, editors. Bioenergetics of wild herbivores. CRC Press, Boca Raton, Florida, USA.

Carbyn, L. N. 1983. Wolf predation on elk in Riding Mountain National Park, Manitoba. Journal of Wildlife Management 47(4):963-976.

Caughley, G. 1981. What is overabundance? Pages 159-187 in P. A. Jewell and S. Holt, editors. Problems in management of locally abundant wild mammals. Academic Press, New York, New York, USA.

Clevenger, A. P., B. Chruszcz, and K. E. Gunson. 2001. Highway mitigation fencing reduces wildlifevehicle collisions. Wildlife Society Bulletin 29 (2):646-653.

Davey, G. 1981. Animal learning and conditioning. MacMillan, London, UK.

DelGiudice, G. D., F. J. Singer, and U. S. Seal. 1991. Physiological assessment of winter nutritional deprivation in elk of Yellowstone National Park. Journal of Wildlife Management 55 (4):653-664.
DelGiudice, G. D., K. D. Kerr, L. D. Mech, and U. S. Seal. 2000. Prolonged winter undernutrition and the interpretation of urinary allantoin:creatinine ratios in white-tailed deer. Canadian Journal of Zoology 78(12):2147-2155.

Domjan, M. 2003. The principles of learning and behavior. Fifth edition. Thomson Wadsworth, Belmont, California, USA.

Espmark, Y., and R. Langvatn. 1985. Development and habituation of cardiac and behavioural responses in young red deer calves (Cervus elaphus) exposed to alarm stimuli. Journal of Mammalogy 66(4):702-711.

Etter, D. R., K. M. Hollis, T. R. Van Deelen, D. R. Ludwig, J. E. Chelsvig, C. L. Anchor, and R. E. Warner. 2002. Survival and movements of whitetailed deer in suburban Chicago, Illinois. Journal of Wildlife Management 66(2):500-510.

Frid, A. 1997. Vigilance by female Dall's sheep: interactions between predation risk factors. Animal Behaviour 53:799-808.

Frid, A., and L. M. Dill. 2002. Human-caused disturbance stimuli as a form of predation risk. Conservation Ecology 6(1):11.

Galef, B. G. 1995. Why behaviour patterns that animals learn socially are locally adaptive. Animal Behaviour 49:1325-1334.

Gander, H., and P. Ingold. 1997. Reactions of male alpine chamois Rupricapra r. rupicapra to hikers, joggers and mountain bikers. Biological Conservation 79(1):107-109.

Gates, C. C., and R. J. Hudson. 1979. Effects of posture and activity on metabolic responses of wapiti to cold. Journal of Wildlife Management 43 (2):564-567.

Geist, V. 1982. Adaptive behavioural strategies. Pages 219-277 in J. W. Thomas and D. E. Toweill, editors. Elk of North America: ecology and management. Stackpole Books, Harrisburg, Pennsylvania, USA.

Goodson, N. J., D. R. Stevens, and J. A. Bailey. 1991. Effects of snow on foraging ecology and 
nutrition of bighorn sheep. Journal of Wildlife Management 55(2):214-222.

Government of Canada. 2000. Canada National Parks Act: an act respecting the National Parks of Canada. Government of Canada, Ottawa, Canada.

Griffin, A. S. 2004. Social learning about predators: a review and prospectus. Learning and Behavior $\mathbf{3 2}$ (1):131-140.

Guynn, J. R., and G. K. Yarrow. 1997. Ecosystem management and wildlife management: compatible or conflicting? Proceedings of the Eastern Wildlife Damage Management Conference, Jackson, Mississippi 7:7-11. Available online at http://wildlifedamage.unl.edu/handbook/Chapters/sech2. doc.

Harlow, H. F. 1932. Social facilitation of feeding in the albino rat. Pedagogical Seminary and Journal of Genetic Physiology 41(1):211-221.

Hebblewhite, M. and D. H. Pletscher. 2002. Effects of elk group size on predation by wolves. Canadian Journal of Zoology 80:800-809.

Herrero, S. 1985. Bear attacks: their causes and avoidance. Hurtig, Toronto, Canada.

Holland, W. D., and G. M. Coen. 1983. Ecological (biophysical) land classification of Banff and Jasper National Parks. Volume 1. Summary. Alberta Institute of Pedology, Edmonton, Canada.

Holroyd, G. L., and K. J. Van Tighem. 1983. Ecological (biophysical) land classification of Banff and Jasper National Parks. Volume 3. The wildlife inventory. Canadian Wildlife Service, Edmonton, Canada.

Hurd, T. E. 1999. Factors limiting moose numbers and their interaction with elk and wolves in the Central Rocky Mountains, Canada. Thesis. University of British Columbia, Vancouver, Canada.

Isbell, L. A., and T. P. Young. 1993. Human presence reduces predation in a free-ranging vervet monkey population in Kenya. Animal Behaviour 45:1233-1235.

Jennings, D. J., M. P. Gammell, C. M. Carlin, and T. J. Hayden. 2002. Does lateral presentation of the palmate antlers during fights by fallow deer (Dama dama L.) signify dominance or submission? Ethology 108:389-401.

Kilpatrick, H. J., and S. M. Spohr. 2000. Spatial and temporal use of a suburban landscape by female white-tailed deer. Wildlife Society Bulletin 28 (4):1023-1029.

Klopfer, P. H. 1957. An experiment in empathic learning in ducks. The American Naturalist 91 (856):61-63.

LaGory, K. E. 1987. The influence of habitat and group characteristics on the alarm and flight response of white-tailed deer. Animal Behaviour 35:20-25.

Lee, M. E., and R. Millar. 2003. Managing elk in the wildland-urban interface: attitudes of Flagstaff, Arizona residents. Wildlife Society Bulletin 31 (1):185-191.

Lima, S. L., and L. M. Dill. 1990. Behavioural decisions made under the risk of predation: a review and prospectus. Canadian Journal of Zoology 68:619-640.

Lubow, B. C., F. J. Singer, T. L. Johnson, and D. C. Bowden. 2002. Dynamics of interacting elk populations within and adjacent to Rocky Mountain National Park. Journal of Wildlife Management 66 (3):757-775.

MacArthur, R. A., V. Geist, and R. H. Johnston. 1982. Cardiac and behavioural responses of mountain sheep to human disturbance. Journal of Wildlife Management 46:351-358.

Martinetto, K., and J.-M. Cugnasse. 2001. Reaction distance in Mediterranean mouflon (Ovus gmelini musimon $x$ ovis sp.) in the presence of hikers with a dog on the Caroux Plateau (Herault, France). Revue d'Ecologie-la Terre et la Vie 56:231-242.

McConnell, P. B., and J. R. Baylis. 1985. Interspecific communication in cooperative herding: acoustic and visual signals from human shepherds and herding dogs. Zeitschrift fur Tierpsychologie 67:302-328.

McCorquodale, S. M. 1993. Winter foraging behavior of elk in the shrub-steppe of Washington. Journal of Wildlife Management 57(4):881-890. 
McCoy, J., and K. Johnston. 2000. Using ArcGIS Spatial Analyst. Environmental Systems Research Institute, Redlands, California, USA.

McCullough, D. R., K. W. Jennings, N. B. Gates, B. G. Elliott, and J. E. DiDonato. 1997. Overabundant deer populations in California. Wildlife Society Bulletin 25(2):478-483.

McGuire, T. M., and J. F. Morrall. 2000. Strategic highway improvements to minimize environmental impacts within the Canadian Rocky Mountain National Parks. Canadian Journal of Civil Engineering 27:523-532.

McKenzie, J. A. 2001. The selective advantage of urban habitat use by elk in Banff National Park. Thesis. University of Guelph, Guelph, Canada. Available online at

http://www.collectionscanada.ca/obj/s4/f2/dsk3/ftp04/ MQ61927.pdf.

McNay, M. E. 2002a. A case history of wolf-human encounters in Alaska and Canada. Alaska Department of Fish and Game Wildlife Technical Bulletin 13. Available online at

http://wildlife.alaska.gov/pubs/techpubs/research pdfs/ techb13 full.pdf.

McNay, M. E. 2002b. Wolf-human interactions in Alaska and Canada: a review of the case history. Wildlife Society Bulletin 30(3):831-843.

Mech, L. D. 1970. The wolf: the ecology and behavior of an endangered species. Doubleday/ Natural History Press, Garden City, New York, USA.

Mech, L. D., and S. M. Barber. 2002. A critique of wildlife radio-tracking and its use in national parks: a report to the U.S. National Park Service. U.S. Geological Survey, Northern Prairie Wildlife Research Center, Jamestown, North Dakota, USA. Available online at

http://www.npwrc.usgs.gov/resource/wildlife/radiotrk/ radiotrk.htm.

Messmer, T. A., S. M. George, and L. Cornicelli. 1997. Legal considerations regarding lethal and nonlethal approaches to managing urban deer. Wildlife Society Bulletin 25(2):424-429.

Miller S., R. Knight, and C. Miller. 2001. Wildlife responses to pedestrians and dogs. Wildlife Society
Bulletin 29(1):124-132.

Moen, A. N. 1976. Energy conservation by whitetailed deer in the winter. Ecology 57(1):192-198.

Morellet, N., and B. Guibert. 1999. Spatial heterogeneity of winter forest resources used by deer. Forest Ecology and Management 123:11-20.

Muller-Schwarze, D. 1991. The chemical ecology of ungulates. Applied Animal Behaviour

Science 29:389-402.

National Park Service. 1991. Natural resources management guidelines. U.S. Department of the Interior, Washington, D.C., USA.

Nietvelt, C. G. 2001. Herbivory interactions between beaver (Castor canadensis) and elk (Cervus elaphus) on willow (Salix spp.) in Banff National Park, Alberta. Thesis. University of Alberta, Edmonton, Alberta, Canada. Available online at http://www.nlc-bnc.ca/obj/s4/f2/dsk3/ftp04/MQ60482. pdf.

Nolte, D. L., K. C. Vercauteren, K. R. Perry, and S. E. Adams. 2003. Training deer to avoid sites through negative reinforcement. Pages 95-104 in K. A. Fagerstone and G. W. Witmer, editors. Proceedings of the Tenth Wildlife Damage Management Conference. Wildlife Damage Management Working Group of the Wildlife Society, Fort Collins, Colorado, USA. Available online at

http://www.aphis.usda.gov/ws/nwrc/is/03pubs/nolte0311. pdf.

Norusis, M. 2002. SPSS 11.0 guide to data analysis. Prentice Hall, Englewood Cliffs, New Jersey, USA.

Okarma, H. 1995. The trophic ecology of wolves and their predatory role in ungulate communities of forest ecosystems in Europe. Acta Theriologica 40 (4):335-386.

Parker, K. L., C. T. Robbins, and T. A. Hanley. 1984. Energy expenditures for locomotion by mule deer and elk. Journal of Wildlife Management 48 (2):474-488.

Parker, K. L., M. P. Gillingham, T. A. Hanley, and C. T. Robbins. 1996. Foraging efficiency: energy expenditure versus energy gain in freeranging black-tailed deer. Canadian Journal of 
Zoology 74(3):442-450.

Ralphs, M. H., and F. D. Provenza. 1999. Conditioned food aversions: principles and practices, with special reference to social facilitation. Proceedings of the Nutrition Society 58 (4):813-820.

Reynolds, G. 1975. A primer of operant conditioning. Scott, Foresman and Co., Glenview, Illinois, USA.

Riley, S. P. D., J. Hadidian, and D. A. Manski. 1998. Population density, survival, and rabies in racoons in an urban national park. Canadian Journal of Zoology 76:1153-1164.

Ripple, W. J., and R. L. Beschta. 2004. Wolves and the ecology of fear: can predation risk structure ecosystems? BioScience 54(8):755-766.

Rondeau, D., and J. M. Conrad. 2003. Managing urban deer. American Journal of Agricultural Economics 85(1):266-281.

Rubin, E. S., W. M. Boyce, C. J. Stermer, and S. G. Torres. 2002. Bighorn sheep habitat use and selection near an urban environment. Biological Conservation 104:251-263.

Rybarczyk, P., J. Rushen, and A. M. de Pasille. 2003. Recognition of people by dairy calves using colour of clothing. Applied Animal Behaviour Science 81:307-319.

Schultz, R. D., and J. A. Bailey. 1978. Responses of national park elk to human activity. Journal of Wildlife Management 42(1):91-99.

Smith, B. 1998. Moving 'em: a guide to low stress animal handling. Graziers Hui, Kamuela, Hawaii, USA.

Soulé, M. E., J. A. Estes, J. Berger, and C. M. Del Rio. 2003. Ecological effectiveness: conservation goals for interactive species. Conservation Biology 17(5):1238-1250.

Staines, B. W., and D. Welch. 1989. Impact of red and roe deer on Scottish woodlands. Pages 128-130 in R. J. Putman, editor. Mammals as pests. Chapman and Hall, Edinburgh, UK.

Steere, A. C. 1994. Lyme disease: a growing threat to urban populations. Proceedings of the National Academy of Sciences of the United States of America 91(7):2378-2383.

Sweeney, J. M., and J. R. Sweeney. 1984. Snow depths influencing winter movements of elk. Journal of Mammalogy 65(3):524-526.

Taylor, A. R., and R. L. Knight. 2003. Behavioral responses of wildlife to human activity: terminology and methods. Wildlife Society Bulletin 31 (4):1263-1271.

Thompson, M., and R. Henderson. 1998. Elk habituation as a credibility challenge for wildlife professionals. Wildlife Society Bulletin 26 (3):477-483.

VerCauteren, K. C., S. E. Hygnstrom, M. J. Pipas, P. B. Fioranelli, S. J. Werner, and B. F. Blackwell. 2003. Red lasers are ineffective for dispersing deer at night. Wildlife Society Bulletin 31 (1):247-252.

Warren, R. J. 1991. Ecological justification for controlling deer populations in eastern national parks. North American Wildlife and Natural Resources Conference 56:56-66.

Weaver, J. L. 1994. Ecology of wolf predation amidst high ungulate diversity in Jasper National Park, Alberta. Thesis. University of Montana, Missoula, Montana, USA.

White, C. A., C. E. Olmsted, and C. E. Kay. 1998. Aspen, elk, and fire in the Rocky Mountain national parks of North America. Wildlife Society Bulletin 26 (3):449-462.

Witmer, G. W., and D. G. Whittaker. 2001. Dealing with nuisance and depredating black bears. Western Black Bear Workshop 7:73-81. Available online at

http://www.aphis.usda.gov/ws/nwrc/is/01pubs/01-88. pdf.

Whittaker, D., and R. Knight. 1998. Understanding wildlife responses to humans. Wildlife Society Bulletin 26(2):312-317.

Woods, J. G. 1991. Ecology of a partially migratory elk population. Thesis. University of British Columbia, Vancouver, Canada. 